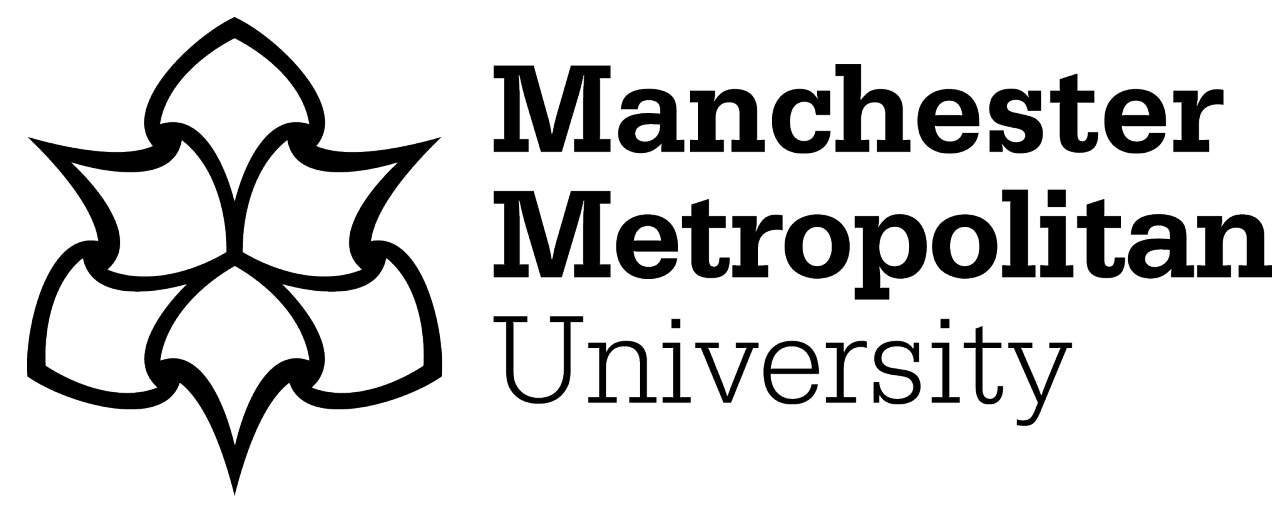

Hill, Matthew and Hurst, Steven (2020) The Trump administration: continuity and change in US foreign policy. Global Affairs, 6 (1). pp. 143-147. ISSN 2334-0460

Downloaded from: https://e-space.mmu.ac.uk/626293/

Version: Accepted Version

Publisher: Informa UK Limited

DOI: https://doi.org/10.1080/23340460.2020.1734960

Please cite the published version 


\section{The Trump Presidency: Continuity and Change in US Foreign Policy}

In examining the Trump administration's foreign policy practice and strategy, it is all too easy to fixate on the constant flow of outrageous comments made by Trump, and treat this as the best route to determining the administration's approach to engaging with the world. However, picking up on, and running with, the latest tweet with an air of confidence is unlikely to be an approach which will stand up to much scrutiny in the long term.. In an attempt to rectify this tendency to focus on the most immediate and the most outrageous, the articles collected in this special issue have sought to take a self-consciously methodological and theoretical approach to understanding and contextualising the Trump administration's foreign policy in an attempt to provide a more solidly grounded assessment of the extent of foreign policy change that has occurred under the 45 th president of the United States.

It was noted in the introduction to this special issue that, while it was a sine qua non of inclusion for papers to engage with questions of theory and/or methodology, no single theoretical or methodological framework was imposed. The result is a wide-ranging collection of articles that approach the question of Trump and foreign policy change from a diverse range of perspectives. Some of the papers seek to define and measure change in various ways (Deyermond; Ashbee and Hurst; Restad), others focus primarily on explaining change, or the lack of it (Biegon and Watts; Hassan, Holland and Fermor), and some attempt to do both (Kitchen; Siniver and Featherstone). Some of the papers go back to the late nineteenth century, some to the establishment of the post-WWII liberal international order and others to the post-Cold War period. Some focus on domestic factors and others on the international environment. One paper places a heavy emphasis on system structure (Biegon and Watts) while others are extremely agent-centred (Siniver and Featherstone). Several of 
the papers emphasize ideational factors while one (Biegon and Watts) takes a firmly (historical) materialistic approach to change. Nevertheless, for all their diversity of approach, the papers speak to a common set of questions relating to Donald Trump, foreign policy change and problems of theory and methodology, and in consequence, a number of clear themes can be identified.

The question from which this SI originally arose was whether Donald Trump's foreign policy does, or does not, represent a radical change from or rupture with those of his immediate and near predecessors. As we indicated in the introduction, there was no expectation that the employment of theory would somehow miraculously resolve this question, and such has proved to be the case. Some of the authors conclude that there have been major changes, even paradigmatic ones, in US foreign policy under Trump (Deyermond, Hassan, Kitchen). Others are equally clear that there have not (Biegon and Watts). Still others, in accordance with the observation that it is still rather early to draw definitive conclusions, take a more cautious view, seeing signs of incipient change but not yet full blown policy transformation (Ashbee and Hurst; Holland and Fermor). What matters more than the diversity of the conclusions, however, are the theoretical and methodological processes by which they were arrived at and what we can learn by their comparison.

One of the points made in the introduction was that the ongoing debate about the Trump foreign policy lacks serious engagement with the question of how we go about defining and measuring change, a weakness which characterizes the FPA literature on change more broadly. As Pierson (2001) has observed, "it is impossible to seriously evaluate competing explanations when there is no agreement about the pattern of outcomes to be explained". In this SI, Ashbee and Hurst address this problem most directly. Having identified the paucity of 
engagement with this problem in the FPA literature, they develop a framework for measuring change derived from historical institutionalism, presidential scholarship, economic history and above all from the work of Karl Polanyi. The framework they employ is composed of ideas (paradigms), interests, institutions and logics of action. In addition to concluding that, measured with this framework, there are clear but not yet definitive indications of foreign policy transformation under Trump, they also suggest that, contra the argument of most existing FPA work addressing this question, transformational change does not necessarily occur simultaneously across the full spectrum of a nation's foreign policy. Rather, it may in fact develop differentially and incrementally, evolving in different areas at different times and at different speeds. Whilst this complicates the process of identifying transformational change, it also provides a more nuanced understanding of change and offers one explanation as to why there are such divergent conclusions in this SI. On this reading of how change happens, findings of major change in policy towards Russia alongside findings of continuity in counter-terrorism policy are not, in and of themselves, necessarily either problematic or decisive proof of anything with regard to the transformation of overall US foreign policy.

Ashbee and Hurst also touch on an issue which is further developed in the articles by Restad and Hassan, namely the importance of being clear about the historical baseline against which change is measured. Much of the commentary about Trump and change is framed in terms of his rejection of liberal internationalism. Yet the assumed existence of LI as the paradigm against which to measure such change is itself problematic. According to Ashbee and Hurst, for example, the Republican Party has long since abandoned LI in favour of conservative internationalism. Restad, for her part, argues that ethnic nationalism should be incorporated into our examination of US foreign policy, and questions the assumption that civic nationalism is overwhelmingly dominant in the shaping of US foreign policy. In examining 
Trump's foreign policy she acknowledges his rejection of liberal internationalism and notes that if we accept the dominant view of civic/liberal nationalism as the historic norm then Trump represents ruptural change. However, by arguing that ethnic nationalism is more prominent in the American mind-set than previously assumed, she questions the conventional narrative and suggests that Trump's nationalist foreign policy contains more elements of continuity than many suppose.

Biegon and Watts make a similar point from a slightly different perspective in their observation about the importance of taking a longue duree approach to assessing change. Nevertheless, their argument stands out in this collection primarily because of its emphasis on structure rather than agency. In rejecting the idea that Trump has initiated radical foreign policy change, they emphasise material structural factors in their argument. On one level, therefore, they recite an argument that has been widely made elsewhere, namely that while there has been a rhetorical and tactical shift by the Trump administration in how it conceives and attains its foreign policy objectives, there has been less or no change in concrete policies. In their case, however, this claim is underpinned by a clear theoretical framework - that of historical materialism - which explains why that is the case. In their view, regardless of his rhetoric or his inclinations, Trump has been compelled to continue the pursuit of the 'War on Terror' and US counter-terrorist policy by the structural requirements of the US politicaleconomy and the maintenance of hegemonic leadership.

Unlike Biegon and Watt's unreserved application of historical materialism, the clear preference of a majority of authors in this SI is for an emphasis on ideational factors, whether this takes the form of 'paradigms' (Ashbee and Hurst; Kitchen), social constructivism (Deyermond; Hassan) or a Gramscian discursive war of position (Holland and Fermor). For 
the most part, those who emphasize ideas also tend to be those who are more likely to identify significant foreign policy change as having occurred under Trump (though this is not a necessary relationship, as Holland and Fermor's paper demonstrates). This, in turn, reflects a theoretical approach which more or less inverts that employed by Biegon and Watts. Whereas for the latter ideas are essentially epiphenomenal, in many of the other analyses ideational shifts are the driving force of change. As such it is logical that ideational shifts will come first and that material changes will then follow.

Those arguments that emphasize ideas also offer an implicit or explicit critique of the rhetoric/reality distinction which is so often wheeled out by those who insist on the essential continuity in US foreign policy under Trump. For constructivists, in particular, such a distinction is meaningless since "rhetoric" and "reality" are not separate phenomena but mutually constitutive ones. The material world ("reality") is socially constructed rather than objectively given. ${ }^{1}$ Language and ideas shape and form the material world and our understandings thereof. The ideational elements carried by languag, develop over time and if repeated frequently enough (via education, the media and other processes) become widely embedded in a society. Once an ideology is thus established, these shared ideas form the context within which political actors behave and the frame within which they make choices. Ideas thus matter, according to these arguments, because they change "reality" and in doing so affect the course of foreign policy. Perhaps the clearest example of this line of argument is to be found in Ruth Deyermond's article. In her analysis of US foreign policy during and after the Cold War, she outlines the way in which being an examplar and defender of global democracy has been a central dimension of US Post-Cold War foreign policy and national identity (and arguably for much longer than that). Trump's embrace of Vladimir Putin and open disregard for the latter's contempt for democratic norms consequently "threatens the 
stability of the wider national narrative of which this identity is a part: the narrative of American exceptionalism." In sum, if Trump can reshape Americans' understanding of their own national identity (public and elite actors) he changes the framework through which they view the world and shifts the ideological constraints on the policy options available to policymakers as a result.

Another line of argument often produced in discussions about Trump and change is that the $45^{\text {th }}$ president is so mercurial and unpredictable that no pattern, whether of continuity or change, is discernible. The analyses in this SI generally reject that claim, both in terms of their identification of clear patterns of behaviour in Trump's foreign policy and in terms of the common elements, which re-occur across the papers. The populist-nationalist nature of Trump's ideology, for example, is a common denominator of several papers. Siniver and Featherstone make the argument for Trump's consistency most explicitly. Employing a leadership traits framework originally developed by Margaret Hermann, amongst others, they argue that Trump displays low conceptual complexity in his thinking and this has led to his consistent employment of a simplistic economic-transactional ("plutocratic") prism in which all issues are viewed in terms of relative economic gains (or losses) for the US.

A final element common to a number of the articles is that, in seeking to identify theoretical or methodological tools that enable them to get to grips with the problem of Donald Trump and foreign policy change, the authors find themselves resorting to fields of analysis other than FPA or International Relations Theory in order to do so. Holland and Fermor derive their theoretical framework from a Gramscian analysis developed in order to understand the potential for revolutionary change in Italy. Three other articles (Ashbee and Hurst. Hassan, Kitchen) borrow in different ways from Peter Hall's (1993) seminal article, whose analysis of 
different levels or "orders" of change was based on a study of changes in economic policy paradigms in the UK. In so doing, these papers highlight a point touched on earlier in this conclusion. At least part of the reason that there has been little theoretically and methodologically derived analyses of the Trump presidency and foreign policy change is due to a paucity of appropriate tools. While there has been considerable discussion of possible independent variables/causes of change (see Ashbee and Hurst), the literature remains fragmented and under-developed. There is a proliferation of competing ideas, but little by way of any subsequent evolution, no winnowing out of arguments or increasing sophistication of theory. When it comes to the question of how to define or measure change the FPA literature is even more scant.

If we are to make progress in defining, measuring and understanding foreign policy change, therefore, we need to start by developing better theoretical and methodological tools for the task. The articles in this SI have, we believe, made a modest, but not insignificant, contribution to that objective. Nothing here is assumed to be definitive. None of us believe that what we have written is the last word in the analysis of either the Trump foreign policy or foreign policy change more generally. Nevertheless, these articles do take the debate forward because of their explicit engagement with questions of theory and method. Regardless of whether they conclude that Trump has, or has not, instituted a radical break in the course of US foreign policy, the premises and assumptions underlying their conclusions are articulated for all to see. That, in turn allows for a meaningful and progressive debate in which theoretical and methodological assumptions can be interrogated, challenged, revised and refined. In the long run the result will be better theory and an improved ability to identify when foreign policy change has occurred and why it has done so. We are not there yet, but this collection is a step in the right direction. 


\section{References}

Hall, P. A. (1993). Policy paradigms, social learning, and the state: The case of economic policymaking in Britain. Comparative Politics, 25 (3), 275-296.

Pierson, Paul (2001) Coping with Permanent Austerity: Welfare State Restructuring in Affluent Democracies, pp. 410-56. in Paul Pierson (ed.), The New Politics of the Welfare State, Oxford: Oxford University Press.

\footnotetext{
${ }^{1}$ We note though that there are differences amongst social constructivists and that some take a rather more limited line, arguing only for the constructed nature of social reality rather than the totality of material reality.
} 